\title{
Article \\ The Vulnerability of Emerging Sign Languages: (E)merging Sign Languages?
}

\author{
Marah Jaraisy ${ }^{1, *}$ and Rose Stamp ${ }^{2}$ (1) \\ 1 Department of English Language and Linguistics, University of Birmingham, Birmingham B15 2TT, UK \\ 2 Department of English Literature \& Linguistics, Bar-Ilan University, Ramat Gan 5290002, Israel; \\ rose.stamp@biu.ac.il \\ * Correspondence: mxi150@student.bham.ac.uk
}

check for updates

Citation: Jaraisy, Marah, and Rose Stamp. 2022. The Vulnerability of Emerging Sign Languages:

(E)merging Sign Languages?

Languages 7: 49. https://doi.org/ 10.3390/languages7010049

Academic Editors: Mark Aronoff, Wendy Sandler and Carol Padden

Received: 26 October 2021

Accepted: 25 January 2022

Published: 24 February 2022

Publisher's Note: MDPI stays neutral with regard to jurisdictional claims in published maps and institutional affiliations.

Copyright: (C) 2022 by the authors. Licensee MDPI, Basel, Switzerland. This article is an open access article distributed under the terms and conditions of the Creative Commons Attribution (CC BY) license (https:// creativecommons.org/licenses/by/ $4.0 /)$.

\begin{abstract}
Emerging sign languages offer linguists an opportunity to observe language emergence in real time, far beyond the capabilities of spoken language studies. Sign languages can emerge in different social circumstances-some in larger heterogeneous communities, while others in smaller and more homogeneous communities. Often, examples of the latter, such as Ban Khor Sign Language (in Thailand), Al Sayyid Bedouin Sign Language (in Israel), and Mardin Sign Language (in Turkey), arise in communities with a high incidence of hereditary deafness. Traditionally, these communities were in limited contact with the wider deaf community in the region, and so the local sign language remained relatively uninfluenced by the surrounding signed language(s). Yet, in recent years, changes in education, mobility, and social communication patterns have resulted in increased interaction between sign languages. Rather than undergoing language emergence, these sign languages are now facing a state of "mergence" with the majority sign language used by the wider deaf community. This study focuses on the language contact situation between two sign languages in Kufr Qassem, Israel. In the current situation, third-generation deaf signers in Kufr Qassem are exposed to the local sign language, Kufr Qassem Sign Language (KQSL), and the dominant sign language of the wider Israeli deaf community, Israeli Sign Language (ISL), both of which emerged around 90 years ago. In the current study, we analyzed the signing of twelve deaf sign-bilinguals from Kufr Qassem whilst they engaged in a semi-spontaneous task in three language conditions: (1) with another bilingual signer, (2) with a monolingual KQSL signer, and (3) with a monolingual ISL signer. The results demonstrate that KQSL-ISL sign-bilinguals show a preference for ISL in all conditions, even when paired with a monolingual KQSL signer. We conclude that the degree of language shift in Kufr Qassem is considerable. KQSL may be endangered due to the risk of social and linguistic mergence of the KQSL community with the ISL community in the near future.
\end{abstract}

Keywords: language shift; mergence; Israeli Sign Language; Kufr Qassem Sign Language; bilinguals; language preference

\section{Introduction}

Emerging sign languages have received increased attention in the field of linguistics in recent decades (see Snoddon and De Meulder 2020). Studies on emerging sign languages predominantly focus on the "emerging" element of these languages; in other words, how these sign languages offer us a unique opportunity to observe the emergence of languages. However, the vulnerability of these languages within an emerging context is often overlooked. From an outsider's perspective, some of these languages appear to be thriving in a regionally bound community in which deaf and hearing individuals sign. However, the language vitality for many emerging sign languages is not as stable as it may appear. By the time linguists are aware of their presence, they may already be at risk of merging with the national sign language in the region, as has been reported in a few sign languages (Dikyuva 2012; Jaraisy 2021; Nonaka 2004; Stamp and Jaraisy 2021). 
In this paper, we focus on the sociolinguistic situation of emerging sign languages and potentially the biggest threat to their vitality: language shift. The threat of language shift occurs when a community gradually increases their use of a particular language at the expense of their own (Karan 2011). For example, Nonaka $(2004,2012)$ describes the situation of an emerging sign language ${ }^{1}$, Ban Khor Sign Language (BKSL), used in the Ban Khor village in northeastern Thailand, and its increased contact with Thai Sign Language (TSL), the national sign language of Thailand. She argues that younger generations of deaf people in Ban Khor are shifting from the use of BKSL towards TSL as their primary language. In her study, she describes the increased use of language contact phenomena such as code-switching and lexical borrowing from TSL as one indication that language shift is taking place. This case of language shift, along with similar cases in other language communities, have been attributed to increased social mobility and the recent establishment of deaf classes in rural areas, which in turn leads to increased contact between smaller local sign languages and larger national sign languages (Nonaka 2012, 2014; Stamp and Jaraisy 2021). Because many emerging sign languages are characterized by smaller communities and a lack of prestigious status and institutional support, the social status of emerging sign languages when in contact with a larger national sign language is reduced to that of a minority language. Therefore, when contact occurs, some emerging sign languages can be considered as endangered as soon as they arise.

In this paper, we look at the language contact situation taking place in Kufr Qassem, Israel, between Kufr Qassem ${ }^{2}$ Sign Language (KQSL) and Israeli Sign Language (ISL) — two emerging sign languages with different social characteristics. While both sign languages are of a similar age-less than 100 years old (Kastner et al. 2014) — they emerged into communities with different social situations, as we describe in Section 1. Following this, we provide details about the factors that influence language vitality (Section 2.1), and we give different examples of language shift presented in the sign language literature (Section 2.2). In the current study, we examine language shift by looking at the distribution of ISL and KQSL lexical signs in the sign language repertoires of young bilinguals who reside in Kufr Qassem, Israel. In Section 3, we provide a detailed description of the methods used to elicit a range of productions by experimentally manipulating the interlocutor. We present the results in Section 4, which show a strong preference among KQSL-ISL sign-bilinguals towards the use of ISL, even when they converse with a monolingual KQSL signer. In the Discussion, in Section 5, we suggest that language shift is taking place in Kufr Qassem, and we discuss the considerations one should make when working with emerging sign languages. In Section 6, we consider language endangerment within the broader context of language vitality-looking at the life cycle of sign languages from their emergence to their mergence.

\section{Background}

Emerging sign languages are defined in the literature as "new" sign languages, which emerge when deaf people with no shared means of communication form a community and they have the necessity to communicate using a visual language (Meir et al. 2010). There has been debate in the literature as to what degree we can describe these languages as "new" (Russo and Volterra 2005). When sign languages emerge, users have at their disposal the gestural repertoires of the wider community to build on (Coppola and Senghas 2010; Mesh 2017; Mesh and Hou 2018; Polich 2005; Senghas et al. 2004). In fact, all sign languages, emerging and otherwise, are considered to be young when compared with spoken languages, which often developed from older languages or were in contact with other languages. British Sign Language (BSL), for example, which is one of the oldest recorded sign languages, is estimated to be only 260 years old. Emerging sign languages, however, often include signers from the first generation of the language. This gives linguists the chance to track emergence in "real time" by examining how the language changes from its first generation to the current one. Often, emerging sign languages are contrasted with established ones, which, although young, are more difficult to trace back 
to their first generations (e.g., BSL). Recently, scholars have problematized the different ways in which researchers classify sign languages (e.g., Hou and de Vos 2021). The term "emerging", for example, is a rather broad classification, grouping together sign languages in terms of their relative youth ("emerging" vs. "established") (Fenlon and Wilkinson 2015; Le Guen et al. 2020; Zeshan and de Vos 2012), regardless of their different social circumstances. Other studies classify sign languages based on the community size: "macro" vs. "micro" (Schembri 2010), the geographical location: "urban" or "rural" (de Vos 2011), or their distribution and status: "national" (Woodward 2000). For the purpose of this study, "emerging" does not capture the difference we see between two sign languages of a similar age (such as the two sign languages under investigation in this study: Israeli Sign Language and Kufr Qassem Sign Language). These two languages exist in different social conditions, and it is these social conditions that are important in the discussion of their vulnerability. Therefore, in this study, we use terminology which refers to the social situations of different types of emerging sign languages, those known as "deaf community" and "village" sign languages (Meir et al. 2010). We argue that the vulnerability of each type of emerging sign language is different and cannot be determined by the languages' "emerging" status alone, but rather based on their relative status and contact with other sign languages. In other words, when two sign languages co-exist geographically, often one is dominant in relation to the other, leading to a situation of language shift.

In this paper, we examine the vulnerability of emerging sign languages which fall into two types: deaf community sign languages and village sign languages. A deaf community sign language emerges when deaf people from different backgrounds come together in a local deaf school, thereby forming a deaf community. For example, in Nicaragua, the educational system for deaf people was oralist, and the language of instruction was Spanish until the 1970s (Polich 2005). Teachers observed deaf children's use of gestures to communicate with each other, although there was no conventional language at a community level (Polich 2005). In 1977, a new educational program opened in Nicaragua, and a larger number of deaf students enrolled. Signing gradually made its way into the classroom; teachers started using signs and gestures with the students, and students increased their use of sign and gesture with one another, both inside and outside of the classroom. This change created an environment for a sign language to emerge (Polich 2005; Senghas 1995). Nicaraguan Sign Language (NSL) as it is known today is mainly linked to the establishment of the deaf community in a school environment.

Emerging sign languages of the second type, village sign languages, originate under different social conditions and are not linked to the establishment of a school community (Meir et al. 2010). Rather, a sign language arises in a small community into which several deaf children are born. This is more likely to occur in communities with consanguineous marriage in which the gene for congenital deafness is often passed on within the family (Meir et al. 2010). In these communities, because of the high numbers of deaf people, a sign language emerges. Often, hearing relatives sign with varying degree of proficiency. For this reason such languages are also described as "shared sign languages" (Kisch 2008; Nyst 2010). Al-Sayyid Bedouin Sign Language (ABSL), which emerged in a Bedouin community located in the Negev desert in Southern Israel $^{3}$, is one example of a village sign language. The community has a much higher incidence of deafness $(2.89 \%)$ compared to the other communities around the world (e.g., 0.07\% in the USA, Marazita et al. 1993), with around 130 deaf people in a population of 4500 (Kisch 2012). It is claimed that ABSL first emerged around 90 years ago when four deaf children were born into the same family. Now, in its fourth generation, ABSL has been studied extensively by researchers of emerging sign languages (Kisch 2008, 2012; Meir et al. 2010; Sandler 2012).

Deaf community sign languages and village sign languages exist in different sociolinguistic situations. The former, deaf community sign languages, are often used by larger communities, with heterogeneous language and social backgrounds and relatively limited shared knowledge, while the latter, village sign languages, are used by smaller, close-knit communities with shared culture and knowledge. For these reasons, studies 
show that there are observable differences in the linguistic structure of these two types of sign languages, most notably in terms of linguistic convergence (Meir and Sandler 2019). In a study by Meir and Sandler (2019), the authors compared two emerging sign languages in Israel, both of a similar age: one, a deaf community sign language, ISL, and the other a village sign language, ABSL. Specifically, they found that ABSL was characterized by more variability than ISL at all levels of the language, and that some linguistic structures developed earlier in ISL than in ABSL (Meir and Sandler 2019; Sandler 2012). The authors argue that these linguistic differences are attributed to the different social contexts of ISL and ABSL, claiming that there is a stronger pressure towards conventionalization in a deaf community sign language than in a village sign language. Table 1 summarizes some of the key differences between deaf community and village sign languages.

Table 1. Social situation of deaf community and village sign languages (Meir et al. 2010).

\begin{tabular}{ccc}
\hline & Deaf Community Sign Languages & Village Sign Languages \\
\hline Size of the community & Larger & Smaller \\
Distribution of deaf people & Dispersed & Close-knit \\
Shared knowledge & Less shared knowledge & More shared knowledge \\
Composition of community & Mostly deaf & Deaf and hearing (in many cases) \\
\hline
\end{tabular}

In another study, which compared ABSL with another village sign language used in Israel, Kufr Qassem Sign Language (KQSL), differences were also found (Stamp and Sandler 2021). The results of the study showed that ABSL was conventionalizing at a faster pace than KQSL. The authors attributed this difference to the distinctive social dynamics of ABSL and KQSL. Although these two sign languages are of a similar age (i.e., 90 years old) and language type (i.e., village sign language), they differ in the proportion of deaf people in relation to the general population. In Kufr Qassem, the proportional population is much smaller than in Al Sayyid, with 120 deaf people in a general population of 23,000 compared to 130 deaf people in a general population of 4500, respectively. This may have an impact on language contact and transmission patterns, known to influence rates of conventionalization (Nonaka 2012; Richie et al. 2014). In summary, the social situation of emerging sign languages is fundamental to their character, more so than their language age, and factors including community size, social structure, and status are key measures of language vitality, to which we turn next.

\subsection{Sign Language Endangerment \& Ethnolinguistic Vitality}

Some scholars argue that all sign languages are endangered (e.g., Schembri 2010), and yet sign language endangerment has been a relatively under-studied topic (Braithwaite 2019) until recently (see Snoddon and De Meulder (2020)). In an attempt to better understand a language's level of endangerment, several assessments of language vitality have been applied to sign languages, including ones by Ethnologue (Eberhard et al. 2021), UNESCO's endangered language survey (Safar and Webster 2014; Webster and Safar 2019), and the Ethnolinguistic Vitality Model (Giles et al. 1977). Ethnologue, which publishes an annual list of living languages, developed an adapted method for assessing the vitality of sign language communities (Bickford et al. 2015; Eberhard et al. 2021). A summary of several sign languages listed within Ethnologue appears in Table 2. Importantly, while most deaf community sign languages are rated as "developing"4 (e.g., ISL), not all village sign languages reach the same status. In fact, in comparison, KQSL, which was added to Ethnologue in 2020, is classified as "threatened" 
Table 2. Ethnolinguistic status of several sign languages.

\begin{tabular}{|c|c|c|c|c|}
\hline Language & Language Type & Community Size & $\begin{array}{l}\text { Language Status } \\
\text { (according to } \\
\text { Ethnologue) }\end{array}$ & $\begin{array}{c}\text { Language Status } \\
\text { (according to } \\
\text { UNESCO) }\end{array}$ \\
\hline $\begin{array}{l}\text { Kufr Qassem Sign Language } \\
\text { (Israel) }\end{array}$ & Village & 120 deaf people (Sarsour 2020) & $6 \mathrm{~b}$ (Threatened) & $\mathrm{n} / \mathrm{a}$ \\
\hline $\begin{array}{c}\text { Al Sayyid Bedouin Sign } \\
\text { language (Israel) }\end{array}$ & Village & 140 deaf people (Sandler et al. 2005) & 6a (Vigorous) & $\begin{array}{l}\text { 3-definitely } \\
\text { endangered }\end{array}$ \\
\hline Kata Kolok (Bali) & Village & 1500 signers (Senghas 2021) & 5 (Developing) & $\begin{array}{l}\text { 3-definitely } \\
\text { endangered }\end{array}$ \\
\hline $\begin{array}{c}\text { Ban Khor Sign Language } \\
\text { (Thailand) }\end{array}$ & Village & 400 signers (Nonaka 2012) & 6a (Vigorous) & $\begin{array}{l}2 \text {-severely } \\
\text { endangered }\end{array}$ \\
\hline $\begin{array}{c}\text { Nicaraguan Sign Language } \\
\text { (Nicaragua) }\end{array}$ & $\begin{array}{c}\text { Deaf } \\
\text { community }\end{array}$ & 3000 signers (Parks 2012) & 5 (Developing) & $\mathrm{n} / \mathrm{a}$ \\
\hline Israeli Sign Language (Israel) & $\begin{array}{l}\text { Deaf } \\
\text { community }\end{array}$ & 10,000 signers (Meir et al. 2010) & 5 (Developing) & $\mathrm{n} / \mathrm{a}$ \\
\hline
\end{tabular}

Another tool for assessing language vitality is UNESCO's endangered languages survey "Language vitality and endangerment". Until recently, this list only included spoken languages, but in 2011, it was adapted for signed languages (Safar and Webster 2014; Webster and Safar 2019). The adapted survey included questions about a variety of factors, including the size of a community in relation to the wider community, language use across age groups, domains of use (e.g., home vs. school), institutional attitudes and policies, community members' attitudes towards the language, etc. The scoring process resulted in a rating from 0 to 5, with zero as "extinct" and five as "safe". Findings on the analysis of an initial 15 sign languages revealed that not a single sign language was rated as "safe" (see scores for relevant sign languages in Table 2). More specifically, it was found that village sign languages were threatened by the dispersal of the language community, changes in marital patterns, and decreasing birth rates of deaf children (Braithwaite 2019; Safar and Webster 2014; Zeshan and Dikyuva 2013). In contrast, deaf community sign languages were threatened by advancements in cochlear implants and the loss of sign language in schools (Johnston 2006). The languages most threatened by extinction were the ones with the smallest community sizes (i.e., 40-100).

Clearly, more work is necessary as the ratings for some sign languages across Ethnologue and UNESCO are unaligned. For example, according to Ethnologue, Kata Kolok (KK) is rated as "developing", a relatively positive rating, but according to UNESCO, it is "definitely endangered". The results show that while both deaf community sign languages and village sign languages are endangered, the reasons for their endangerment may differ.

According to Giles et al.'s (1977) Ethnolinguistic Vitality Model, a language community's vitality is measured on three parameters: demographics (i.e., the community's size), institutional support, and status. In other words, smaller language communities with less widely distributed populations have lower ethnolinguistic vitality than larger communities with more widely distributed populations. Language communities with limited institutional support-whether financial, legal, or educational-are considered to have a lower vitality. Finally, language communities with a lower status, in terms of political, economic, and social status, have a lower vitality. Put in these ethnolinguistic vitality terms, we ask: which factors might affect the vitality of emerging sign languages? We consider each of Giles et al.'s (1977) factors below within the context of these sign language types:

\subsubsection{Demographics: Community Size}

Community size refers to the number of language users (speakers or signers). When sign languages first emerge, they are likely to arise with small numbers of signers, regardless of the sign language type. However, there are other ways of viewing community size besides numbers of signers. Community size can be described in relative terms-e.g., percentage of deaf members within the wider community-and when this approach is 
taken, the community size is much higher in village sign languages compared to deaf community sign languages. Moreover, community size can also be considered in terms of longevity; that is, the transmission of the language. Is the community likely to grow in forthcoming generations? Language transmission is one of the most important factors in preventing the decline of a language (Fishman 1991), and perhaps even more crucial for sign languages which often face an unusual situation of language transmission (McKee and Manning 2015). This unusual situation is manifested in the fact that most deaf children are born to hearing parents (Mitchell and Karchmer 2004), and therefore many deaf people may not encounter sign language until they enter school, at which point they acquire sign language horizontally from their peers (Hoffmeister 2007). Contrary to this, in village sign languages, due to the higher numbers of adult signers, both hearing and deaf, this is less likely to be the case (Zeshan and de Vos 2012). In summation, community size in terms of absolute number of users renders all emerging sign languages as low in ethnolinguistic vitality. However, in terms of the relative proportion of deaf people in the wider community or language transmission patterns, village sign languages can appear to be more resilient than deaf community sign languages.

\subsubsection{Institutional Support}

Deaf community sign languages emerge as a result of the establishment of educational institutions (Meir et al. 2010), which can be one of the major driving forces in receiving institutional support. For example, in Israel, both ISL and ABSL emerged at similar times, and yet ISL is used in many formal contexts such as education, interpreting programs, and in the media, while ABSL is not. It is worth noting that ISL is not officially or financially supported, as is the case in some other sign languages (e.g., Sign Language of the Netherlands (NGT)); however, ISL is informally recognized as being the national sign language of Israel. The lack of institutional support for ABSL and other village sign languages that emerged in Arab towns and villages in Israel is often politically motivated. That is, in Israel, the Palestinian indigenous minoritized society has a much lower political, social, economic, and linguistic status compared to that of Israeli Jewish majority because of the political situation in the country. These differences in political forces are often reflected in policies and practices implemented by the Israeli government in many domains, including language. Languages used by the Jewish majority, mainly Hebrew, receive more institutional and academic support than languages used by the Palestinian indigenous minorities, mainly Arabic (for more information on the linguistic inequality in Israel, see Amara $(2002,2006)$, Saban and Amara (2002); Shohamy and Ghazaleh-Mahajneh (2012)). These differences in institutional support can also be seen in village sign languages and their deaf communities.

Institutional support can also be informal, e.g., within industry, religion, culture, etc. In the adaptation of the UNESCO assessment of language vitality, Webster and Safar (2019) point out that the use of a language in public domains (e.g., education, media, etc.) is viewed as a determining factor of strong language vitality compared to the use of a language in private domains (e.g., home), despite the importance of the home in language transmission in village sign language communities. Additionally, they state that the importance of organizations and activities is often overlooked in these assessments. In Kufr Qassem, for example, the deaf club, set up in 1996, has become the cornerstone of the deaf community. There is an important relationship between status and institutional support in that sign languages which receive institutional support are likely to have a higher status, or vice versa, to which we turn next.

\subsubsection{Status of the Language}

Status may refer to economic, social, sociohistorical, political, or linguistic status. Language status and institutional support are closely related. When one language receives support, this can create an association between one particular language and progress (e.g., the use of ISL and obtaining a job or education). In such cases, other languages in the region may be viewed as outdated and unnecessary by default (May 2012). As 
described in Section 2.1.2, the difference in political power leads to a situation of linguistic inequality, and lower sociopolitical and economic status (among other types of inequality and discrimination), in which village sign languages are viewed as lower in status than deaf community sign languages (such as ISL).

Linguistic status can be viewed from inside and outside of the community (Giles et al. 1977). In other words, the status of a village sign language may be viewed positively from inside of the community, including the hearing community, but negatively outside of the community by the wider deaf and hearing communities. In village sign language communities, for example, there is usually less stigma around the notion of deafness and the use of sign languages. However, the status of the village sign language from outside of the community might be relatively low. That said, an in-depth investigation to determine the attitudes and ideologies in relation to KQSL is necessary, similar to studies by Safar (2015) and Moriarty Harrelson (2017).

According to Giles et al.'s Ethnolinguistic Vitality Model, emerging sign language communities, mainly village sign language communities, are low in ethnolinguistic vitality. What is more important, though, is the relative ethnolinguistic vitalities of language communities in a contact situation. In cases where a deaf community sign language is in contact with a village sign language, the latter is usually more vulnerable, and its users are likely to shift towards the language with a higher vitality. We discuss this topic below.

\subsection{Language Contact and Shift}

When two or more languages are in contact, language users in this community often become efficient users of these languages. Continual contact between the languages can result in language contact phenomena such as code-switching and borrowing, or even language shift (Milroy and Muysken 1995; Thomason 2001). Language shift occurs when one language is increasingly used at the expense of the other, leading to a shift in usage (Kulick 1992). Even though this is one of the most common causes of language endangerment in spoken languages (Austin and Sallabank 2013), it is claimed that it may be occurring more rapidly for sign languages (Braithwaite 2019). In particular, when village sign languages are in contact with national sign languages, they are more likely to undergo language shift towards the latter, due to the former's minority status.

Language shift has been reported in several sign language communities which at first had little contact with the wider deaf community. Due to changes in social mobility in recent years, they are now in contact with the national sign language (Groce 1985; Yoel 2009). A famous case is Martha's Vineyard Sign Language (MVSL), a sign language which emerged on Martha's Vineyard Island located off the shores of Connecticut, USA. Nora Groce's (1985) book, entitled "Everyone Here Spoke Sign Language", reports that due to the relatively high incidence of hereditary deafness in the population, a sign language emerged on the island. MVSL was used by both deaf and hearing islanders, which facilitated communication, and thereby minimized some of the limitations typically faced by deaf people. MVSL use gradually declined due to a number of reasons, including changes in marital practices and movement to the mainland for work. In 1817, the first deaf school was opened in Hartford, Connecticut on the mainland, and was attended by many deaf children from Martha's Vineyard. It was claimed that several signing practices, including home signs, MVSL, and French Sign Language (i.e., the teacher's language in the first class), merged to form what we know today as American Sign Language (ASL) (Padden 2010; Romm 2015). In 1952, the last fluent signer of MVSL died, which marked the extinction of MVSL. Similar contact scenarios are evident in the history of other sign languages, such as Maritime Sign Language, which developed due to migration of deaf people from the UK and US to Canada (Yoel 2009).

Another example is the case of Ban Khor Sign Language (BKSL), a village sign language used in Thailand. BKSL emerged around 80-100 years ago (Nonaka 2004, 2012) in a small rice-cultivating population with a relatively high percentage of deaf people (i.e., 1 in 100). The deaf community in Ban Khor was once isolated from the wider deaf community, 
and therefore uninfluenced by the national sign language, Thai Sign Language (TSL). However, in recent years, deaf people in Ban Khor became increasingly mobile for work and education, leading to an increased contact between BKSL and TSL. Nonaka (2012) also claims that due to the promotion of TSL by educational and governmental institutes, the status of TSL increased within the BKSL community. This has led to a rise in language contact phenomena such as code-switching and lexical borrowing from TSL into BKSL, even within the core vocabulary. Nonaka $(2004,2012)$ argues that the increase in language contact phenomena serve as evidence of language shift from BKSL to TSL.

Evidence of language shift has also been reported in Israel, the site of the current study. Israel is known for its sign language diversity, hosting both indigenous and migrant sign languages. Algerian-Jewish Sign Language (AJSL), a sign language used by a Jewish community who immigrated from Ghardaia, Algeria to Israel, has been the subject of studies on language survival and extinction. Lanesman and Meir (2012) reported that when the first generation of AJSL signers moved to Israel, they married outside of their community and increasingly interacted with the wider deaf ISL community for work and education. Consequently, the younger generation shifted towards the use of ISL. As a result, Lanesman and Meir (2012) predict that AJSL will inevitably become extinct. In a similar case, Yoel (2007) found evidence of language shift and attrition of Russian Sign Language (RSL) in Israel. In the 1990s, a large wave of Russians immigrated to Israel, resulting in a community of Russian Sign Language (RSL) users of around one thousand. Yoel (2007), who found a decline in the use of RSL, interpreted her results in light of Giles et al.'s (1977) Ethnolinguistic Vitality Model, arguing that the higher ethnolinguistic vitality of ISL (compared to RSL) led to first language (L1) attrition among RSL signers. These results were evident in a number of ways, one of which is an increase in language contact phenomena, such as code-switching from ISL to RSL.

The use of a national sign language in deaf education can also result in a rapid shift from one language to another. Many first-generation deaf signers in Israel did not receive a formal education, and some did not receive any education. This was especially the case in village sign language communities, such as Al-Sayyid and Kufr Qassem. Nowadays, it is common that younger deaf people attend school in both urban and rural parts of Israel. Deaf children in Al-Sayyid and Kufr Qassem have been in contact with other deaf children from outside of their community since the 1980s, and communication mostly takes place in ISL. As a result, younger generations of deaf signers in Al-Sayyid, for example, are now bilingual in ABSL and ISL, and in some cases, even monolingual in ISL (Kisch 2012). Kisch (2012) describes how ABSL and ISL are used in different settings (domains): ABSL is used mostly in informal settings, such as exchanges in shops, conversations, and storytelling; and ISL is used mostly in formal settings for a diverse range of exchanges (e.g., medical, legal, education). Language shift from ABSL to ISL is underway in the ABSL deaf community, but the degree of this shift among younger generations has yet to be investigated.

\subsection{The Current Study}

In the current study, we explore the degree of language shift taking place in the Kufr Qassem deaf community in Israel, in which the younger generation are now exposed to two sign languages, the local sign language, Kufr Qassem Sign Language (KQSL), and the national sign language of Israel, Israeli Sign Language (ISL). We focus on the signing behaviors of twelve KQSL-ISL sign-bilinguals from Kufr Qassem in order to assess the impact of increased contact between KQSL and ISL. We ask the following research questions: Is there evidence of language shift in the signing behavior among the younger generations of the Kufr Qassem deaf community? If yes, what is the degree of this language shift? What can this tell us about the vulnerability of emerging sign languages (in contact situations)?

To this end, we quantify the language used by our KQSL-ISL bilinguals in three language interaction conditions: with another bilingual, a monolingual ISL signer, and a monolingual KQSL signer, thereby eliciting a wide range of repertoires from these 
young deaf signers. We predict that signers will accommodate their signing behaviors in accordance with the interlocutor's language background in each condition: i.e., using ISL predominantly in the ISL condition and KQSL predominantly in the KQSL condition.

\section{Methods}

In this section, we give an overview of the sign language communities under investigation: KQSL and ISL. Following this, we describe the methods in this study including details about participants, stimuli, procedure, and data coding and analysis.

\subsection{Communities under Investigation}

Israel is home to several smaller sign language communities-in Kufr Qassem, AlSayyid, Abu Kaf, Ein Mahel, and Arab Al-Naim among others, all of which emerged in the early 20th century in what is known today as Israel (see Figure 1). Kufr Qassem is a Palestinian-Arab town which has existed for hundreds of years, situated in the Southern Triangle area in Central Israel, around $20 \mathrm{~km}$ northeast of Tel-Aviv. As a result of the relatively high incidence of hereditary deafness in Kufr Qassem, a local village sign language, known as Kufr Qassem Sign Language (KQSL), emerged around 90 years ago. It is claimed that this sign language arose when a deaf woman from the Negev area married a hearing man from Kufr Qassem and they had deaf children together (Kafr Qasem Sign Language Dictionary-Sign Language Research Lab 2013). The deafness gene was passed on from one generation to the next and, gradually, the deaf population grew from 12 in the 1960s to 30 in the 1970s. With the increasing deaf population came the necessity for a class for deaf children, which was opened in 1979 in the local school in Kufr Qassem (Kafr Qasem Sign Language Dictionary-Sign Language Research Lab 2013). In 1985, ISL was introduced to the deaf class when a teacher competent in ISL joined the class. Today, of its 23,000 residents (Central Bureau of Statistics: Kfar Qassem 2019), approximately 120 are deaf, spanning four generations (Sarsour 2020). Deaf and hearing people sign with varying degrees of proficiency.

Over the last fifty years, there have been significant changes in the social mobility and educational policies for deaf children across Israel, including in Kufr Qassem. Deaf people from the first generation of KQSL signers, now elderly members of the community, did not attend school and therefore remained relatively uninfluenced from other signed and spoken languages ${ }^{6}$. Some deaf signers of the second generation attended the first deaf class in Kufr Qassem. Others attended the deaf class after 1985 when a teacher competent in ISL joined the class, and therefore they were exposed to ISL within the classroom (Kafr Qasem Sign Language Dictionary-Sign Language Research Lab 2013). Recent studies show that changes are taking place in the signing behavior of the first- and second-generation deaf signers in Kufr Qassem (Jaraisy 2021; Stamp and Jaraisy 2021). While the first- and second-generation of deaf signers are predominantly KQSL monolinguals, their signing behavior shows evidence of language contact phenomena such as code-switching and lexical borrowing from ISL (an average of $15 \%$ of the overall lexical signs produced) (Jaraisy 2021; Stamp and Jaraisy 2021). Third and fourth generations of deaf people in Kufr Qassem are exposed to ISL at school and in the wider deaf community, within the medical, sports, legal, and interpreting services, as well as social media. Moreover, younger deaf people are also exposed to other languages, including Arabic (Colloquial Arabic and Modern Standard Arabic), Hebrew, and English. Mostly through international travel and social media (e.g., $\mathrm{TV}$, internet, Twitter), some young signers are exposed to other signed languages used in different countries-such as ASL, BSL, etc. Despite this, signers are exposed to these sign languages intermittently and in some cases without interaction (e.g., television). For this study, we do not examine the effects of exposure to other signed languages, used predominantly outside of Israel, on the signing behavior of the young signers of Kufr Qassem deaf community, although this may be of interest for future studies. 


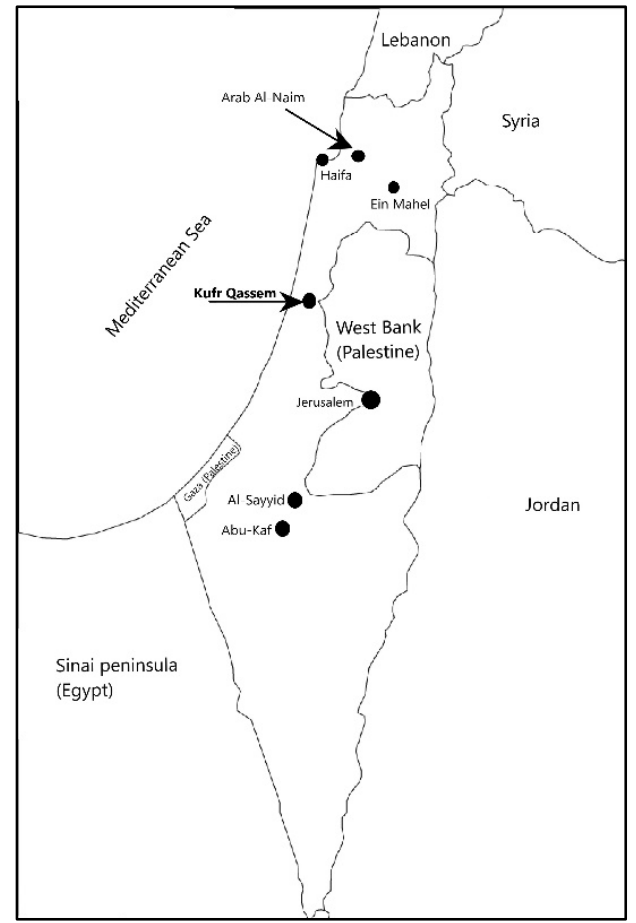

Figure 1. Map of Israel with the locations of several sign language communities.

Today, younger deaf people in Kufr Qassem are multilingual in several sign languages, as well as written and spoken languages. In this study, we explore the effect of language contact between KQSL and ISL on sign language use and preferences among KQSL-ISL deaf sign-bilinguals. While ISL and KQSL are estimated to be of the same age, the sociolinguistic situation of each community is vastly different, as outlined in Section 2. ISL is a deaf community sign language which arose with the formation of the deaf community in Israel in the 1930s. It is often dated to the establishment of the first school for the deaf set up in 1932 in Jerusalem. Previous studies have likened the emergence of ISL to the process of creolization because of the influence of many different signing systems on the lexicon of ISL, including signs from Germany and other European countries, but also from Morocco, Algeria, and Egypt (Aronoff et al. 2008; Sandler 2013). Today, ISL is widely used by around 10,000 signers (Kastner et al. 2014). In contrast, KQSL is an example of a village sign language used by a much smaller population. Despite their shared geography and age, KQSL and ISL are historically unrelated. A lexical comparison study conducted by Kastner et al. (2014) confirmed that KQSL is independent from ISL and also ABSL. Table 3 presents a comparison of the characteristics of ISL and KQSL.

Table 3. Comparison of ISL and KQSL characteristics.

\begin{tabular}{cc}
\hline Israeli Sign Language (ISL) & Kufr Qassem Sign Language (KQSL) \\
\hline Larger heterogeneous population (Meir et al. 2010) & Smaller homogeneous population (Meir et al. 2012) \\
Used by 10,000 signers (Kastner et al. 2014) & Deaf population: 120 (Sarsour 2020) \\
Used widely within media, education and interpreting & Used only in informal contexts: the local community \\
General population (Israel): Roughly 9 million (Population of \\
Israel on the Eve of 2020 2019) & $\begin{array}{c}\text { General population (Kufr Qassem): roughly 23,000 (Central } \\
\text { Bureau of Statistics: Kfar Qassem 2019) }\end{array}$ \\
\hline
\end{tabular}

\subsection{Participants}

Twelve deaf bilingual signers ( 5 female: 7 male) were recruited for this study, ranging in age from 22 to 46 years (average age: 29 years). All participants are self-reported KQSL-ISL sign-bilinguals, and this was further corroborated by our deaf contact person from the community who is also a KQSL-ISL sign-bilingual. Participants completed a ques- 
tionnaire about their family background, language preferences and use, and educational experience. They all grew up in Kufr Qassem, exposed to KQSL in the community and/or through family and friends. Most participants graduated from different mainstream high schools where the language of instruction was predominantly ISL. Participant 01 received formal education in the first deaf class before ISL was introduced, and she reported that she acquired ISL later in life through friends and social interaction with the wider deaf community. Some were taught in designated deaf classes in mainstream schools, while others had access to an ISL interpreter in the classroom. Participant characteristics are summarized in Table 4.

Table 4. Participant characteristics.

\begin{tabular}{cccc}
\hline Participant & Age & Gender & Language of Instruction \\
\hline 01 & 46 & $\mathrm{~F}$ & KQSL \\
02 & 32 & $\mathrm{~F}$ & ISL \\
03 & 30 & $\mathrm{M}$ & ISL \\
04 & 26 & $\mathrm{M}$ & ISL \\
05 & 26 & $\mathrm{M}$ & ISL, signed Hebrew, signed \\
06 & 22 & $\mathrm{~F}$ & ISL \\
07 & 37 & $\mathrm{~F}$ & ISL \\
08 & 24 & $\mathrm{~F}$ & ISL, written and signed Arabic \\
09 & 37 & $\mathrm{~F}$ & ISL \\
10 & 24 & $\mathrm{M}$ & ISL, written and spoken Hebrew, \\
11 & 25 & $\mathrm{M}$ & ISL, written and spoken Arabic \\
12 & 23 & M & ISL spoken Hebrew \\
\hline
\end{tabular}

In addition to the twelve deaf bilinguals, two sign-monolinguals were recruited to act as consistent conversational partners in the semi-spontaneous task, described in Section 3.3 below. Each of these conversational partners represented a different language condition, one for KQSL and one for ISL. The KQSL sign-monolingual (female, 44 years old) is a second-generation deaf KQSL signer with KQSL as her first language, who attended the deaf class in Kufr Qassem when ISL was yet not used. The ISL sign-monolingual (female, 31 years old) is a deaf ISL signer (ISL as her first language) from a deaf family with no previous knowledge of KQSL. Each of the monolinguals were instructed to use their L1 sign languages and to simply engage in the conversational task with each new participant.

Filming took place in the deaf club in Kufr Qassem. A deaf contact person was responsible for recruiting participants and running the tasks. Participants signed a consent form before taking part in this study. Consent forms and questionnaire were offered in Arabic and in Hebrew, and all instructions were explained to the participants in their preferred language. This study was approved by the Ethics Committee at Bar-Ilan University. All participants were compensated for their time.

\subsection{Stimuli}

Participants completed three tasks. Only the spot the difference task was analyzed as part of this study. The material in this study-i.e., the cartoon illustrations-were designed and created by the first author as part of her MA studies. The design of these illustrations were based on similar material in previous studies (Baker and Hazan 2011; Stamp 2013). The task was designed specifically to create a semi-spontaneous interaction while controlling for the production of a number of lexical items. These target items are lexical signs that differ between KQSL and ISL, and thereby created a situation of lexical competition. For example, in the left picture shown in Figure 2, a signer can describe the dog sleeping under the table by producing a lexical sign for "dog", which is signed differently in KQSL and ISL. There was a total of 32 items and concepts in the pictures, which are signed differently in ISL compared to KQSL. However, many items were repeated during 
the task, and all were analyzed. The items were chosen carefully based on a number of resources, including online dictionaries and material, a KQSL dictionary (Kafr Qasem Sign Language Dictionary_Sign Language Research Lab 2013), an ISL dictionary (Israeli Sign Language Dictionary 2015), and an online resource on some lexical differences between ISL and KQSL (Berger 2017); in addition to data from previous studies (Jaraisy 2021; Stamp and Jaraisy 2021), and consultation with deaf L1 signers in the KQSL and ISL communities, respectively.
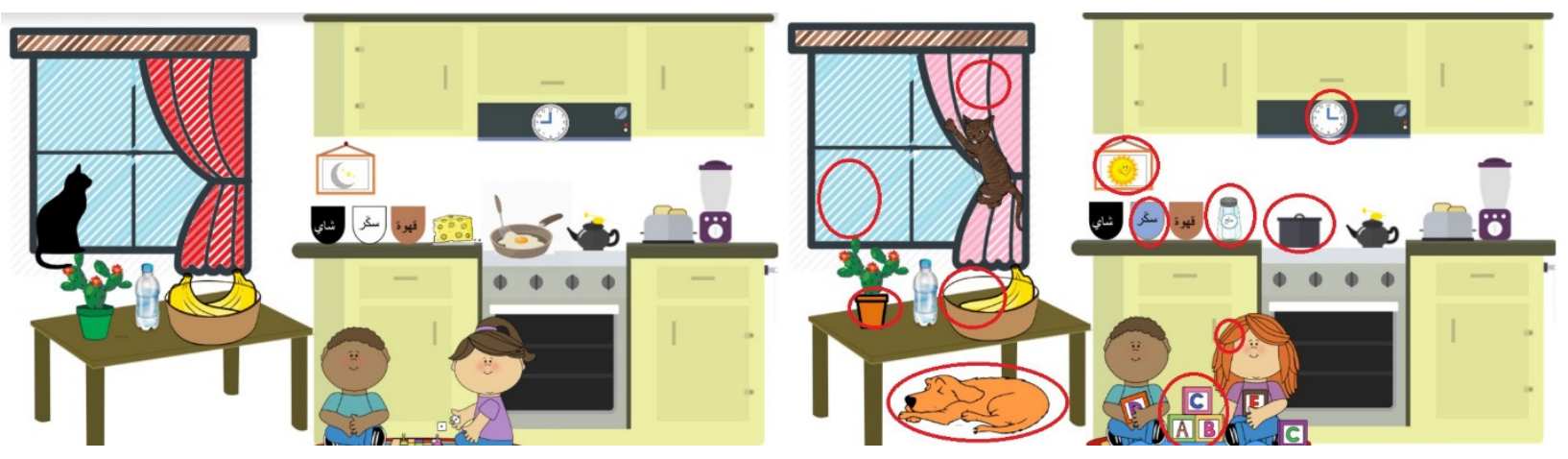

Figure 2. Example of a completed picture scene (kitchen scene); on the right is the picture with twelve differences circled.

\subsection{Procedure}

Signers performed the task in a dyadic setup, in which they were requested to find a total of twelve minor differences between two versions of an altered cartoon illustration of a scene (see Figure 2 as an example) by conversing with their interlocuter. The pictures were presented on laminated sheets, and each signer could only see their own picture and not the picture of their partner. One signer was given the role of circling the differences. This role was alternated between scenes in the task (i.e., different cartoon illustrations). The task was repeated twice with the same interlocutor, each time using a different cartoon illustration.

Participants completed this task in three conditions: (1) with another KQSL-ISL bilingual signer, (2) with a monolingual KQSL signer, and (3) with a monolingual ISL signer. Therefore, there was a total of six picture scene pairs: (1) kitchen (as in Figure 2), (2) field, (3) street, (4) beach, (5) living room, and (6) riverbank. Participants engaged in other tasks in between conditions, to ensure that the task was not repetitious.

\subsection{Data Coding and Analysis}

On average, the completion of all three scenes took $15 \mathrm{~min}$, ranging from 8-20 min. Data were coded using ELAN, a video annotation software (Crasborn and Sloetjes 2008). Only the target lexical items, which differ between KQSL and ISL, were coded for this task. Language preference was quantified across individuals and conditions based on the percentage of the lexical signs in each language from the overall produced lexical signs. For example, if the signer produced a total of 80 tokens in their retelling task, of which 63 are KQSL (78.75\%), then the preferred language is KQSL.

We carried out multivariate statistical analyses of the data using Rbrul (Johnson 2009). Similar to GoldVarb program developed by Rand and Sankoff (1991), Rbrul can quantitatively evaluate the influence of multiple factors on variation. In addition, Rbrul uses mixed-effects modeling to group individual responses accounting for the effects of individual differences (Baayen et al. 2008; Jaeger 2008). 


\section{Results}

The results are presented here in terms of language preference across with the condition (i.e., participants conversed with another KQSL-ISL bilingual, a KQSL monolingual, and an ISL monolingual). A total of 2754 tokens were included as part of this analysis.

Table 5 shows the individual differences in KQSL use in each condition, and on average (for all three conditions). The use of KQSL lexical signs among bilinguals ranged from 2.8 to $63.6 \%$, with an average of $17.1 \%$. On average, most participants preferred the use of ISL in all conditions, with the exception of one participant-KQSL-ISL bilingual no. 06-who used more KQSL on average (63.6\%) than ISL, although less KQSL than ISL in the monolingual ISL condition.

Table 5. Individual variation of KQSL.

\begin{tabular}{cccccc}
\hline \multirow{2}{*}{ Participant } & Tokens & $\begin{array}{c}\text { \% of KQSL } \\
\text { (All Conditions) }\end{array}$ & Bilingual & Mono KQSL & Mono ISL \\
\cline { 4 - 6 } & & $37.3 \%$ & $56 \%$ & $44 \%$ & $5 \%$ \\
01 & 142 & $31.6 \%$ & $70 \%$ & $20 \%$ & $3 \%$ \\
03 & 174 & $7.2 \%$ & $13 \%$ & $8 \%$ & $0 \%$ \\
04 & 207 & $9.4 \%$ & $8 \%$ & $14 \%$ & $4 \%$ \\
05 & 324 & $17.3 \%$ & $72 \%$ & $5 \%$ & $3 \%$ \\
06 & 302 & $63.6 \%$ & $17 \%$ & $0 \%$ & $31 \%$ \\
07 & 253 & $5.5 \%$ & $0 \%$ & $13 \%$ & $0 \%$ \\
12 & 212 & $7.5 \%$ & $14 \%$ & $19 \%$ & $0 \%$ \\
11 & 265 & $11.7 \%$ & $5 \%$ & $13 \%$ & $3 \%$ \\
12 & 262 & $7.3 \%$ & $2 \%$ & $5 \%$ & $2 \%$ \\
\end{tabular}

KQSL lexical sign use varied across participants depending on the condition. In Figure 3, the percentage of KQSL lexical sign use is presented by individual (1-12 on the $X$ axis) and by condition (blue is the bilingual condition, orange is the monolingual KQSL condition, and gray is the monolingual ISL condition). As shown in Figure 3, KQSL was rarely used in the monolingual ISL condition (i.e., all grey bars are low). For the other two conditions, some participants used more KQSL lexical signs in the monolingual KQSL condition than in the bilingual condition, while others showed the reverse pattern. For example, bilingual 01 shows a decline in KQSL lexical sign use as follows: bilingual > monolingual KQSL > monolingual ISL; while bilingual 06 shows a decline in KQSL lexical sign use in a different order: monolingual KQSL > bilingual > monolingual ISL. In some cases, e.g., bilinguals 02 and 10, participants showed a strong increase in KQSL in the monolingual KQSL condition, but overall, showed a preference for ISL. In contrast, several participants did not change their signing across conditions, using ISL predominantly regardless of whom they interacted with (see Table 5).

We conducted a multiple regression analysis to test whether participants' use of KQSL was predictable by condition. Use of KQSL was included as the dependent variable, and condition as the independent variable. Participant was included as a random effect. The results indicated a significant effect of condition on the use of KQSL at a significance level of $p<0.001\left(1.46 \times 10^{-40}\right)$. In the bilingual condition, KQSL lexical signs constituted an average of $24 \%$ of the overall lexical sign production, $20.6 \%$ in the KQSL monolingual condition, and only $4.8 \%$ in the ISL monolingual condition. Table 6 presents the results, including the log odds, number of tokens analyzed, percentage of KQSL lexical signs, and the centered weight (with KQSL lexical signs as the application value). Results with a positive log-odd and a factor weight over 0.5 indicate an increased likelihood that KQSL will be used; while a negative log-odd and a factor weight below 0.5 indicate an increased likelihood that ISL will be used. 


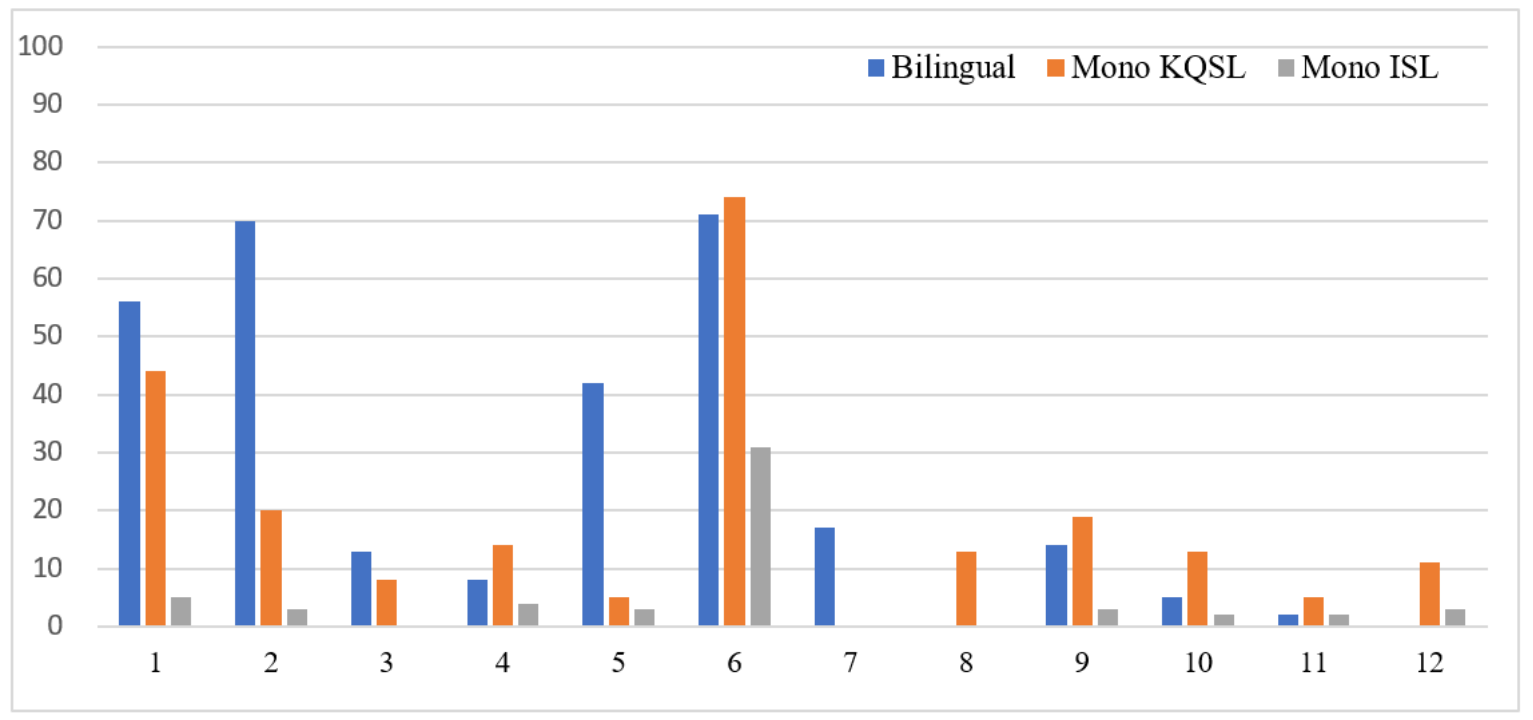

Figure 3. Percentage of KQSL lexical sign use by individual, presented across conditions.

Table 6. Significant Rbrul results (by condition).

\begin{tabular}{ccccc}
\hline Factor Group & Log-Odds & Tokens & \% of KQSL & Centered Weight \\
\hline Condition & & & & \\
Bilingual & 0.966 & 965 & $24.2 \%$ & 0.724 \\
Monolingual KQSL & 0.481 & 1057 & $20.6 \%$ & 0.618 \\
Monolingual ISL & -1.447 & 732 & $4.8 \%$ & 0.191 \\
\hline Application value: KQSL signs. Significant at $p<0.01 .2754$ tokens. Random (participant) standard deviation $=1.225$.
\end{tabular}

\section{Discussion}

This study explored the language contact situation in the Kufr Qassem deaf community. More specifically, the study focused on the younger deaf people who are now exposed to at least two sign languages: the local sign language: KQSL, and the deaf community sign language: ISL, which is used by the wider deaf Israeli community. We examined the linguistic situation for these deaf sign-bilinguals by considering one of the biggest threats to KQSL's continuity: language shift. To return to the question posed earlier in the paper: Is there evidence of language shift in the signing behavior among the younger generations in the Kufr Qassem deaf community? The answer is yes. What is the degree of this language shift? Language shift can be measured in terms of language preference as well as the existence of language contact phenomena, including code-switching and lexical borrowing. The results of our study focus on language preference in a range of language conditions which elicit a wide use of KQSL and ISL. Previous studies have shown that KQSL monolinguals from the first and second generations are KQSL dominant with an average of $85 \%$ of their overall lexical sign use from KQSL (Jaraisy 2021; Stamp and Jaraisy 2021). Therefore, our findings from the third generation provide evidence of an extreme language shift taking place in the Kufr Qassem deaf community, from predominantly using the local village sign language in the first and second generations (Jaraisy 2021; Stamp and Jaraisy 2021), to predominantly using the national sign language, ISL, by the third generation, with an average of $83 \%$ across all conditions (i.e., $17 \%$ KQSL lexical signs on average).

Increased code-switching and lexical borrowing from one language to the other can also be an indication of language shift (Kisch 2012; Nonaka 2004; Yoel 2007). Previous studies show an increase in code-switching and lexical borrowing among the younger bilinguals in Kufr Qassem. Code-switching from ISL into KQSL was more prevalent in the third-generation signers (27\%) than in the first and second generations (15\%) (Jaraisy 2021; 
Stamp and Jaraisy 2021). For example, the sign for "girl", when repeated in a compound meaning "spouse" in KQSL, was replaced with the ISL sign with the equivalent meaning in $62 \%$ of the cases produced by bilinguals, compared to $5 \%$ and $26 \%$ of the first and second generations, respectively (Stamp and Jaraisy 2021). While code-switching and lexical borrowing are types of lexical replacement and language change, they differ in their permanency status in the recipient language (Haspelmath 2009; Myers-Scotton 1992). Codeswitching is a temporary language change, while lexical borrowing is more permanent. Evidence of lexical borrowing was found in the first generation of KQSL signers (Stamp and Jaraisy 2021), suggesting that permanent change as a result of language contact is underway. The data in this current study show similar results, with $83 \%$ of the cases of the sign "girl" produced in ISL by bilinguals across all language conditions.

The language shift observed here highlights the vulnerability of KQSL as a minority village sign language in Israel. The social assimilation of the KQSL deaf community into the wider deaf community in Israel, mainly through education, work, and other social interactions, has been increasing since the 1980s, beginning with the first deaf class in Kufr Qassem. This social assimilation is reflected in the linguistic mergence evident in this study. It is worth noting that this linguistic mergence is gradual and domain specific. That is, KQSL is used at home and with hearing and deaf relatives by some bilinguals, while ISL is used in wider domains, such as education and work. In another study, it was found that KQSL and ISL are used in different topics of discussion. When examining the language use by bilingual KQSL-ISL signers during guided conversations, KQSL was used more when discussing "local" topics (e.g., local foods, traditions) than "global" topics (e.g., education, travel) (Haj Dawood, in prep $^{7}$ ). The reasons for such language shift may vary, but the higher ethnolinguistic vitality of ISL compared to KQSL is a clear factor. Learning ISL has numerous benefits for members of the deaf community in Kufr Qassem, especially younger ones, including access to education, interpreting services, and social interaction with the wider deaf community in Israel. Furthermore, the deaf club in Kufr Qassem, while central to the social interaction of the community and serving as a proud advocate for KQSL, provides ISL classes as part of its social activities. This reflects the fact that ISL receives institutional support, including funding for deaf teachers and interpreters, while KQSL does not (see Sections 2.1.2 and 2.1.3 on motives for this kind of imbalance).

According to Mufwene (2017), one should consider language endangerment within the broader context of language vitality, that is, the entire life cycle of a language from its birth to its death. The term "merging" was used in this study to describe the situation in Kufr Qassem to highlight the threatened status of these sign languages, which might be predictable by some of the characteristics relating to the social situation of emergence (e.g., the relatively small community size), and to the wider general social changes underway, including the increase in social mobility and changes in educational practices. The mergence picture, however, is more complex than presented here. As mentioned in Section 3.1, the participants in this study, as most of the young deaf people in Kufr Qassem, are bimodal multilinguals who make the most of their multilingualism by translanguaging on a daily basis (De Meulder et al. 2019; Kusters et al. 2017). Most younger signers are exposed to Colloquial Arabic, Modern Standard Arabic, Hebrew, and in some cases, English. Changes in education in the Kufr Qassem deaf community not only increased exposure to ISL, but also changed the nature and degree of exposure to Arabic-which is more systematic and extensive now compared to that which was experienced by the older generations (Jaraisy 2021). We suggest that future studies examine the situation in more depth by considering the language situation in terms of multimodality and translanguaging practices (De Meulder et al. 2019; Kusters et al. 2017). Our data show that young signers use multiple languages when signing, in both manual and non-manual features: KQSL, ISL, Arabic mouthing, and Hebrew mouthing ${ }^{8}$. Mouthing patterns and frequency are beyond the scope of this paper; for a detailed account as to the language contact situation between KQSL and Arabic and Hebrew, see Jaraisy (2021) and Jaraisy and Stamp (in prep). 
The bigger picture question here might be: Is language shift inevitable for emerging sign languages? Despite the language shift situation for KQSL signers, the answer more generally is no. As discussed in the background, the ethnolinguistic vitality of an emerging sign language community is, in part, dependent on the type of emerging sign language found in a language contact situation. Village sign languages are at a greater risk than deaf community sign languages because of their relative low vitality in terms of their demographics, institutional support and status when in contact with a national majority sign language. Both languages examined in this study, ISL and KQSL, can be classified as emerging but while KQSL is merging towards ISL, ISL is thriving. In other words, the social situation of the sign language community is key. It is for this reason, that we return to the issue we raised at the beginning of the paper with regards to terminology. We emphasize here that it is not necessarily "emerging" sign languages that are vulnerable; it is the social dynamics of the sign language communities involved, and the language contact situation in which they exist. When discussing language shift, the language contact situation in which a sign language exists is important. In other words, the vitality of any sign language is dependent on what it is in contact with. In the past, it was quite possible for one community to remain relatively isolated from another; however, it is difficult to imagine a scenario nowadays without language contact. In fact, many young deaf people are exposed to multiple languages via social media and changing patterns of social interaction (e.g., international deaf events). This, however, is beyond the scope of this paper and we hope that future studies will consider the bigger picture that is taking place, including processes of globalization.

Deaf community sign languages, whilst potentially having their own language endangerment concerns, are less likely to face the threat of sign language shift compared to village sign languages. That said, recent studies show that some deaf community sign languages may be at risk from contact with other sign languages used over a wider global distribution. Recent papers have highlighted the use of ASL (McKee and McKee 2020; Moriarty 2020) and International Sign (Kusters 2020) and their impact on deaf community sign languages in different countries. While village sign languages might be at a greater risk of merging than deaf community sign languages, it is important to consider whether all village sign languages face the same level of risk of discontinuity. To answer our question, language shift does not have to be inevitable for minority village sign languages, even when the ethnolinguistic vitality may predict it. For example, Kusters (2014) claims that Adamorobe Sign Language (AdaSL), a village sign language used in Ghana, continues to thrive, regardless of its contact with Ghanaian Sign Language (GSL). Although deaf children from Adamorobe attend a residential school where they are exposed to GSL, they switch back to AdaSL when they return home (Kusters 2014). Furthermore, people in Adamorobe value AdaSL and sign bilingualism (Kusters 2014). Considering the situation of village sign languages in Israel more specifically, previous studies show that even two village sign languages within Israel may face different social situations, as is the case with ABSL and KQSL (Stamp and Sandler 2021), and that this is an important factor in the rate of language emergence. These same social factors might also determine a language's rate of mergence. Therefore, every language must be examined on an individual basis to truly understand the situation more sensitively than has been achieved so far (Braithwaite 2019; Webster and Safar 2019, 2020). Despite this, there is a sense of inevitability that so long as ISL is thriving and no other signed languages in Israel are given recognition and support, smaller sign languages might soon disappear.

In summary, no two sign languages are alike, and we cannot assess the vulnerability of all emerging sign languages as one group. Languages exist in different countries with different cultural norms, different levels of accessibility, different attitudes and ideologies towards languages and minority rights, and different legal frameworks. As expressed by Webster and Safar (2019), the vitality of a language is not easy to quantify in a numerical score. It is more complex than that; a language might be endangered based on one factor but thriving based on another, and so each language needs to be assessed based on its own 
complexities. The deaf club in Kufr Qassem shows the presence of a thriving deaf community whose members translanguage, using ISL, KQSL, Arabic, among other languages and signing practices. That said, having assessed the situation in KQSL, if we consider the long-term status of this community in relation to the wider deaf community in Israel, the continuity of KQSL is at risk.

\section{Conclusions}

This paper has considered the vulnerability of emerging sign languages in terms of their sociolinguistic contexts and how this might impact their endangerment and continuity. We focused on the case of the deaf community in Kufr Qassem in which the younger generation are now exposed to two sign languages: a local village sign language, KQSL, and a national deaf community sign language, ISL. We see that some emerging sign languages, such as KQSL, face the threat of language shift when they socially and linguistically merge with the wider deaf community in Israel. Some of the sociolinguistic characteristics of some emerging sign languages, like village sign languages,- - such as smaller community size and lack of institutional support-are the very factors that lead to its vulnerability when in contact with a national sign language. At the same time, this fate is not inevitable for all emerging sign languages. Without language contact, many emerging sign languages may not necessarily be at risk.

The focus on emerging sign languages has typically been on the "emerging" elementbased on the fact that young languages may shed light on what the language once looked like and under what conditions they were able to develop and thrive. However, perhaps now is the time to focus on the "sign languages" themselves by documenting them before it is too late-as Nonaka (2004, p. 759) suggests: "many sign languages are dying out or are on the verge of disappearing without ever being recorded or described - a fact that underscores the urgency of remembering these forgotten endangered languages".

The irony is that when linguists learn of an emerging sign language, this might be because it is no longer as isolated as it once was. Thus, when linguists begin conducting studies on these "new" languages it might already be too late. This raises an important question: Should linguists intervene in a situation such as this? Many linguists prefer to document and not to intervene (Flores Farfan and Ramallo 2010) and to leave intervention to the community itself (Braithwaite 2020). There is still much more work to be conducted on emerging sign languages, and the findings from this paper simply emphasize the urgency of this.

Author Contributions: Conceptualization, M.J. and R.S.; methodology, M.J. and R.S.; formal analysis, M.J.; investigation, M.J.; resources, R.S.; data curation, R.S.; writing—original draft preparation, R.S.; writing—review and editing, M.J. and R.S.; visualization, M.J.; supervision, R.S.; funding acquisition, R.S. All authors have read and agreed to the published version of the manuscript.

Funding: This research was funded by the Israeli Science Foundation grant number [2057/20].

Institutional Review Board Statement: The study was conducted in accordance with the Declaration of Helsinki, and approved by the Ethics Committee of Bar-llan University (protocol code 182021 and 08.11.2020).

Informed Consent Statement: Informed consent was obtained from all subjects involved in the study.

Data Availability Statement: The data presented in this study are available on request from the corresponding author. The data are not publicly available due to ethical and privacy reasons.

Acknowledgments: We wish to thank Rawan Sarsour and Tayyeb Badawi for their help with recruitment and running the tasks, in addition to their feedback on certain issues in the data. We also would like to thank Wehda Sarsour, the founder and current manager of the deaf club in Kufr Qassem who was very generous and opened the doors of the deaf club for us during the data collection process. We are grateful to Dalal Sarsour and Ora Ohanin who acted as language consultants from the KQSL and the ISL community, respectively. We thank Roni Beit-Hallahmi who helped, as a fluent ISL signer, to provide different variations of ISL signs as well as information about language use in the 
general Israeli deaf community. Lastly, we wish to thank the deaf community in Kufr Qassem and the participants without whom this study would have never been possible.

Conflicts of Interest: The authors declare no conflict of interest.

\section{Notes}

1 Nonaka (2004) refers to Ban Khor Sign Language as a young indigenous sign language. However, in this paper we use the term "emerging" to focus on the language age.

2 Kufr Qassem is often represented in the literature and in official documents with different orthographies, including Kfar Qassem, Kafr Qassem, Kafr Qasem, Kafr Qassim, Kufr Qassem, etc. In most cases these different spellings represent the pronunciation in different languages (e.g., English, Hebrew, Arabic). In this paper, the orthography follows the Arabic pronunciation to reflect how deaf and hearing people in the community under investigation refer to the name of their hometown (as shown on Ethnologue 2020).

3 When the language first emerged, the region was known as Palestine.

4 According to Ethnologue, a "developing" language is in vigorous use, with standardized literature used by some but not widespread. It has a rating of 5 in the 13-point scale in which 0 is "international" and 10 is "extinct".

5 "Threatened" is rating $6 \mathrm{~b}$ in the 13-point scale and it is described as a language used for face-to-face communication within all generations, but with reducing numbers of users.

6 "Relatively" uninfluenced here means that they were not formally taught any sign language or spoken language. However, KQSL emerged in an Arabic-speaking community and therefore, contact between KQSL and Arabic is inevitable, though under-researched (for discussion of mouthing, see Jaraisy 2021; Jaraisy and Stamp in prep.).

$7 \quad$ Haj Dawood (in prep) The effects of conversation topic (global vs. local) and conversation interlocutor (monolingual vs. bilingual) on code switching. [MA thesis] Univeristy of Haifa.

8 Mouthing is the silent articulation of spoken words usually produced simultaneously with signs. It is an outcome of cross-modal language contact i.e., contact between a spoken language and a signed one (Johnston et al. 2016).

\section{References}

Amara, Muhammad. 2002. The place of Arabic in Israel. International Journal of the Sociology of Language 158: 53-68. [CrossRef]

Amara, Muhammad. 2006. The vitality of the Arabic language in Israel from a sociolinguistic perspective. Adalah's Newsletter $29:$ 1-11. Aronoff, Mark, Irit Meir, Carol Padden, and Wendy Sandler. 2008. The roots of linguistic organization in a new language. In Holophrasis, Compositionality and Proto Language, Special Issue of Interaction Studies. Edited by Derek Bickerton and Michael Arbib. Amsterdam: John Benjamins, vol. 9, pp. 133-49.

Austin, Peter Kenneth, and Julia Sallabank. 2013. Endangered languages: An introduction. Journal of Multilingual and Multicultural Development 34: 313-16. [CrossRef]

Baayen, Rolf Harald, Doug J. Davidson, and Douglas M. Bates. 2008. Mixed-effects modeling with crossed random effects for subjects and items. Journal of Memory and Language 59: 390-412. [CrossRef]

Baker, Rachel, and Valerie Hazan. 2011. DiapixUK: Task materials for the elicitation of multiple spontaneous speech dialogs. Behavior Research Methods 43: 761-70. [CrossRef] [PubMed]

Berger, Noga. 2017. The Secret of the Hidden Language of the Deaf of Kufr Qassem. Tel-Aviv: Ha-Makom. Available online: https: / / www.ha-makom.co.il/article/noga-berger-sign-language-kfar-qasem (accessed on 11 November 2021).

Bickford, J., Albert M. Paul Lewis, and Gary F. Simons. 2015. Rating the vitality of sign languages. Journal of Multilingual and Multicultural Development 36: 513-27. [CrossRef]

Braithwaite, Ben. 2019. Sign language endangerment and linguistic diversity. Language 95: e161-87. [CrossRef]

Braithwaite, Ben. 2020. Ideologies of linguistic research on small sign languages in the global South: A Caribbean perspective. Language $\mathcal{E}$ Communication 74: 182-94. [CrossRef]

Central Bureau of Statistics: Kfar Qassem. 2019. Available online: https://www.cbs.gov.il/he/Settlements/Pages/\%D7\%99\%D7\%9 9\%D7\%A9\%D7\%95\%D7\%91\%D7\%99\%D7\%9D/\%D7\%9B\%D7\%A4\%D7\%A8\%20\%D7\%A7\%D7\%90\%D7\%A1\%D7\%9D.aspx (accessed on 23 November 2020).

Coppola, Marie, and Ann Senghas. 2010. The Path from Point A to Point B: How Gestures Became Language in Nicaraguan Signing. In The Evolution Of Language. Utrecht: World Scientific, pp. 385-86.

Crasborn, Onno, and Han Sloetjes. 2008. Enhanced ELAN functionality for sign language corpora. Paper presented at the 6th International Conference on Language Resources and Evaluation (LREC 2008)/3rd Workshop on the Representation and Processing of Sign Languages: Construction and Exploitation of Sign Language Corpora, Marrakech, Morocco, May 26-June 1; pp. 39-43.

De Meulder, Maartje, Annelies Kusters, Erin Moriarty, and Joseph J. Murray. 2019. Describe, don't prescribe. The practice and politics of translanguaging in the context of deaf signers. Journal of Multilingual and Multicultural Development 40: 892-906. [CrossRef]

de Vos, Connie. 2011. Kata Kolok Color Terms and the Emergence of Lexical Signs in Rural Signing Communities. The Senses and Society 6: 68-76. [CrossRef] 
Dikyuva, Hasan. 2012. Mardin Sign Language: Signing in a "deaf family". Sign Languages in Village Communities: Anthropological and Linguistic Insights 4: 395.

Eberhard, David M., Gary F. Simons, and Charles D. Fennig, eds. 2021. Ethnologue: Languages of the World, 24th ed. Dallas: SIL International. Available online: http:/ / www.ethnologue.com (accessed on 15 December 2021).

Fenlon, Jordan, and Erin Wilkinson. 2015. Sign languages in the world. In Sociolinguistics and Deaf Communities. Edited by Adam C. Schembri and Ceil Lucas. Cambridge: Cambridge University Press, pp. 5-28.

Fishman, Joshua A. 1991. Reversing Language Shift: Theoretical and Empirical Foundations of Assistance to Threatened Languages. Multilingual Matters. Clevedon: Multilingual Matters Ltd., vol. 76.

Flores Farfan, José Antonio, and Fernando Ramallo. 2010. Exploring links between documentation, sociolinguistics, and language revitalization. In New Perspectives on Endangered Languages. Edited by José Antonio Flores Farfan and Fernando Ramallo. Worcester: John Benjamin, pp. 1-12.

Giles, Howard, Richard Bourhis, and Donald Taylor. 1977. Towards a theory of language in ethnic group relations. In Language, Ethnicity and Intergroup Relations. Edited by Howard Giles. London: Academic Press, pp. 307-48.

Groce, Nora Ellen. 1985. Everyone Here Spoke Sign Language: Hereditary Deafness in Martha's Vineyard. Cambridge: Harvard University Press.

Haspelmath, Martin. 2009. Lexical borrowing: Concepts and issues. In Loanwords in the World's Languages: A Comparative Handbook. Berlin: Walter de Gruyter, pp. 35-54.

Hoffmeister, Robert. 2007. Language and the deaf world: Difference not disability. In Language, Culture, and Community in Teacher Education. Edited by Maria Estela Brisk. Mahwah: Lawrence Erlbaum Associates.

Hou, Lina, and Connie de Vos. 2021. Classifications and typologies: Labeling sign languages and signing communities. Journal of Sociolinguistics, 1-8. [CrossRef]

Israeli Sign Language Dictionary. 2015. Israeli Sign Language Dictionary. Available online: https://isl.org.il/en/home-page-2/ (accessed on 31 January 2021).

Jaeger, T. Florian. 2008. Categorical Data Analysis: Away from ANOVAs (transformation or not) and towards Logit Mixed Models. Journal of Memory and Language 59: 434-46. [CrossRef]

Jaraisy, Marah. 2021. Language Change in Kufr Qassem Deaf Community: Intra- and Inter-Modal Language Contact. Master's thesis, Bar-Ilan University, Ramat Gan, Israel.

Johnson, Daniel Ezra. 2009. Getting off the GoldVarb Standard: Introducing Rbrul for Mixed-Effects Variable Rule Analysis. Language and Linguistics Compass 3: 359-83. [CrossRef]

Johnston, Trevor. 2006. W(h)ither the deaf community?: Population, genetics, and the future of Australian sign language. Sign Language Studies 6: 137-73. [CrossRef]

Johnston, Trevor, Jane Van Roekel, and Adam Schembri. 2016. On the conventionalization of mouth actions in Australian Sign Language. Language and Speech 59: 3-42. [CrossRef] [PubMed]

Kafr Qasem Sign Language Dictionary-Sign Language Research Lab. 2013. Available online: https://signlab.haifa.ac.il/index.php/ dictionarytest-2 (accessed on 20 December 2021).

Karan, Mark E. 2011. Understanding and forecasting Ethnolinguistic Vitality. Journal of Multilingual and Multicultural Development 32: 137-49. [CrossRef]

Kastner, Itamar, Irit Meir, Wendy Sandler, and Svetlana Dachkovsky. 2014. The emergence of embedded structure: Insights from Kafr Qasem Sign Language. Frontiers in Psychology 5: 525. [CrossRef]

Kisch, Shifra. 2008. "Deaf Discourse": The Social Construction of Deafness in a Bedouin Community. Medical Anthropology 27: 283-313. [CrossRef]

Kisch, Shifra. 2012. Demarcating generations of signers in the dynamic sociolinguistic landscape of a shared sign language: The case of the Al-Sayyid Bedouin. In Sign Languages in Village Communities: Anthropological and Linguistic Insights, 1st ed. Edited by Ulrike Zeshan and Connie de Vos. Berlin: De Gruyter, pp. 87-126. Available online: https://www.jstor.org/stable/pdf/j.ctvbkjwzx.7.pdf (accessed on 10 June 2020).

Kulick, Don. 1992. Anger, gender, language shift and the politics of revelation in a Papua New Guinean village. Pragmatics 2: 281-96. [CrossRef]

Kusters, Annelies. 2014. Language ideologies in the shared signing community of Adamorobe. Language in Society 43: 139-58. [CrossRef]

Kusters, Annelies. 2020. The tipping point: On the use of signs from American Sign Language in International Sign. Language $\mathcal{E}$ Communication 75: 51-68. [CrossRef]

Kusters, Annelies, Massimiliano Spotti, Ruth Swanwick, and Elina Tapio. 2017. Beyond languages, beyond modalities: Transforming the study of semiotic repertoires. International Journal of Multilingualism 14: 219-32. [CrossRef]

Lanesman, Sara, and Irit Meir. 2012. The survival of Algerian Jewish Sign Language alongside Israeli Sign Language in Israel. In Sign Languages in Village Communities: Anthropological and Linguistic Insights. Edited by Connie de Vos and Ulrike Zeshan. Berlin: De Gruyter Mouton, pp. 153-80.

Le Guen, Olivier, Marie Coppola, and Josefina Safar. 2020. Introduction: How emerging sign languages in the Americas contributes to the study of linguistics and (emerging) sign languages. In Emerging Sign Languages of the Americas. Edited by O. Le Guen, J. Safar and M. Coppola. Berlin: De Gruyter Mouton, pp. 1-32. 
Marazita, Mary L., Lynn M. Ploughman, Brenda Rawlings, Elizabeth Remington, Kathleen S. Arnos, and Walter E. Nance. 1993. Genetic epidemiological studies of early-onset deafness in the US school-age population. American Journal of Medical Genetics 46: 486-91. [CrossRef] [PubMed]

May, Stephen. 2012. Language and Minority Rights: Ethnicity, Nationalism and the Politics of Language. London: Routledge.

McKee, Rachel Locker, and Victoria Manning. 2015. Evaluating Effects of Language Recognition on Language Rights and the Vitality of New Zealand Sign Language. Sign Language Studies 15: 473-97. [CrossRef]

McKee, Rachel, and David McKee. 2020. Globalization, hybridity, and vitality in the linguistic ideologies of New Zealand Sign Language users. Language E Communication 74: 164-81. [CrossRef]

Meir, Irit, Assaf Israel, Wendy Sandler, Carol A. Padden, and Mark Aronoff. 2012. The influence of community on language structure: Evidence from two young sign languages. Linguistic Variation 12: 247-91. [CrossRef]

Meir, Irit, and Wendy Sandler. 2019. Variation and conventionalization in language emergence. In Language Contact, Continuity and Change in the Genesis of Modern Hebrew. Edited by Edit Doron, Malke Rappaport, Yael R. Hovav and Moshe Taube. Amsterdam: John Benjamins Publishing Company, pp. 337-63. Available online: https://benjamins.com/catalog/la.256.13mei (accessed on 13 October 2020).

Meir, Irit, Wendy Sandler, Carol Padden, and Mark Aronoff. 2010. Emerging sign languages. In Oxford Handbook of Deaf Studies, Language, and Education. Oxford: Oxford University Press, vol. 2.

Mesh, Kate. 2017. Points of Comparison: What Indicating Gestures Tell Us about the Origins of Signs in San Juan Quiahije Chatino Sign Language. Ph.D. thesis, The University of Texas, Austin, TX, USA.

Mesh, Kate, and Lina Hou. 2018. Negation in San Juan Quiahije Chatino Sign Language: The integration and adaptation of conventional gestures. Gesture 17: 330-74. [CrossRef]

Milroy, Lesley, and Pieter Muysken. 1995. Introduction: Code-switching and bilingualism research. In One Speaker, Two Languages: Cross-Disciplinary Perspectives on Code-Switching. Cambridge: Cambridge University Press, pp. 1-14.

Mitchell, Ross E., and Michael A. Karchmer. 2004. When Parents Are Deaf Versus Hard of Hearing: Patterns of Sign Use and School Placement of Deaf and Hard-of-Hearing Children. The Journal of Deaf Studies and Deaf Education 9: 133-52. [CrossRef]

Moriarty Harrelson, Erin. 2017. Deaf people with "no language": Mobility and flexible accumulation in languaging practices of deaf people in Cambodia. Applied Linguistics Review 10: 55-72. [CrossRef]

Moriarty, Erin. 2020. "Sign to me, not the children": Ideologies of language contamination at a deaf tourist site in Bali. Language $\mathcal{E}$ Communication 74: 195-203. [CrossRef]

Mufwene, Salikoko. 2017. Language Vitality: The Weak Theoretical Underpinnings of What Can Be an Exciting Research Area. Language 93: e202-23. [CrossRef]

Myers-Scotton, Carol. 1992. Comparing codeswitching and borrowing. Journal of Multilingual and Multicultural Development 13: 19-39. [CrossRef]

Nonaka, Angela. 2004. The forgotten endangered languages: Lessons on the importance of remembering from Thailand's Ban Khor Sign Language. Language in Society 33: 737-67. [CrossRef]

Nonaka, Angela. 2012. Language ecological change in Ban Khor, Thailand: An ethnographic endangerment. In Sign Languages in Village Communities: Anthropological and Linguistic Insights. Edited by Connie de Vos and Ulrike Zeshan. Berlin: De Gruyter Mouton, pp. 277-312. [CrossRef]

Nonaka, Angela. 2014. (Almost) everyone here spoke Ban Khor Sign Languaged Until they started using TSL: Language shift and endangerment of a Thai village sign language. Language \& Communication 38: 54-72.

Nyst, Victoria. 2010. Sign language in West Africa. In Sign Languages: A Cambridge Language Survey. Edited by Diane Brentari. Cambridge: Cambridge University Press, pp. 405-32.

Padden, Carol A. 2010. Sign language geography. In Deaf around the World: The Impact of Language. Edited by Gaurav Mathur and Donna Jo Napoli. Oxford: Oxford University Press, pp. 19-37.

Parks, Elizabeth. 2012. The Deaf People of Nicaragua. SIL Electronic Survey Report 2012-004. Available online: https:/ / www.academia. edu/download/60283335/The_Deaf_People_of_Nicaragua20190813-124553-2lv6qk.pdf (accessed on 5 January 2022).

Population of Israel on the Eve of 2020. 2019. Available online: https://www.cbs.gov.il/en/mediarelease/Pages/2019/Population-ofIsrael-on-the-Eve-of-2020.aspx (accessed on 14 May 2021).

Polich, Laura. 2005. The Emergence of the Deaf Community in Nicaraugua: "with Sign Language You Can Learn So Much". Washington: Gallaudet University Press.

Rand, David, and David Sankoff. 1991. GoldVarb 2.1: A Variable Rule Application for Macintosh. Montréal: Université de Montréal, Centre de Recherches Mathématiques.

Richie, Russell, Charles Yang, and Marie Coppola. 2014. Modeling the Emergence of Lexicons in Homesign Systems. Topics in Cognitive Science 6: 183-95. [CrossRef]

Romm, Cari. 2015. The Life and Death of Martha's Vineyard Sign Language. The Atlantic. Available online: https://www.theatlantic. com/health/archive/2015/09/marthas-vineyard-sign-language-asl/407191/ (accessed on 14 October 2020).

Russo, Tommaso, and Virginia Volterra. 2005. Comment on "Children Creating Core Properties of Language: Evidence from an Emerging Sign Language in Nicaragua". Science 309: 56-56. [CrossRef]

Saban, Ilan, and Muhammad Amara. 2002. The Status of Arabic in Israel: Refiections on the Power of Law to Produce Social Change. Israel Law Review 36: 5-39. [CrossRef] 
Safar, Josefina. 2015. Eine Analyse von Diskursen über Chicán Sign Language (Mexiko). Das Zeichen 101: 434-46.

Safar, Josefina, and Jenny Webster. 2014. Cataloguing Endangered Sign Languages at iSLanDS. Preston: University of Central Lancashire. Sandler, Wendy. 2012. Dedicated gestures and the emergence of sign language. Gesture 12: 265-307. [CrossRef]

Sandler, Wendy. 2013. Vive la différence: Sign language and spoken language in language evolution. Language and Cognition 5: 189-203. [CrossRef]

Sandler, Wendy, Irit Meir, Carol Padden, and Mark Aronoff. 2005. The emergence of grammar: Systematic structure in a new language. Proceedings of the National Academy of Sciences 102: 2661-65. [CrossRef] [PubMed]

Sarsour, Meyad. 2020. Voices of Sign Langauge Communities: Kufr Qassem Sign Language and Deaf Community. Deaf Communities: Past, Present and Future. Haifa: Haifa University.

Schembri, Adam. 2010. Documenting sign languages. In Language Documentation and Description. Edited by Peter K. Austin. London: SOAS, vol. 7, pp. 105-43.

Senghas, Ann. 1995. Children's Contribution to the Birth of Nicaraguan Sign Language. Ph.D. thesis, MIT, Cambridge, UK.

Senghas, Ann. 2021. Connecting Language Acquisition and Language Evolution. In Minnesota Symposia on Child Psychology. Edited by Maria D. Sera and Melissa Koenig. Hoboken: John Wiley \& Sons, Ltd., pp. 57-85. [CrossRef]

Senghas, Ann, Sotara Kita, and Asli Özyürek. 2004. Children Creating Core Properties of Language: Evidence from an Emerging Sign Language in Nicaragua. Science 305: 1779-82. [CrossRef]

Shohamy, Elana, and Marwan Abu Ghazaleh-Mahajneh. 2012. Linguistic landscape as a tool for interpreting language vitality: Arabic as a 'minority' language in Israel. In Minority Languages in the Linguistic Landscape. London: Palgrave Macmillan, pp. 89-106.

Snoddon, Kristin, and Maartje De Meulder. 2020. Introduction: Ideologies in sign language vitality and revitalization. Language $\mathcal{E}$ Communication 74: 154-63. [CrossRef]

Stamp, Rose. 2013. Sociolinguistic Variation, Language Change and Dialect Contact in the British Sign Language (BSL) Lexicon. Ph.D. dissertation, University College London, London, UK.

Stamp, Rose, and Marah Jaraisy. 2021. Language Contact between Israeli Sign Language and Kufr Qassem Sign Language. Sign Language Studies 21: 455-91. [CrossRef]

Stamp, Rose, and Wendy Sandler. 2021. The emergence of referential shift devices in three young sign languages. Lingua 257: 103070. [CrossRef]

Thomason, Sarah Grey. 2001. Language Contact. Edinburgh: Edinburgh University Press.

Webster, Jennifer, and Josefina Safar. 2019. Scoring sign language vitality: Adapting a spoken language survey to target the endangerment factors affecting sign languages. Language Documentation \& Conservation 13: 346-83.

Webster, Jenny, and Josefina Safar. 2020. Ideologies behind the scoring of factors to rate sign language vitality. Language E Communication 74: 113-29. [CrossRef]

Woodward, James. 2000. Sign languages and sign language families in Thailand and Vietnam. In The Signs of Language Revisited. Edited by Karen Emmorey and Harlan Lane. New York: Psychology Press, pp. 23-47.

Yoel, Judith. 2007. Evidence for first-language attrition of Russian Sign Language among immigrants to Israel. In Sign Languages in Contact. Edited by David Quinto-Pozos. Washington, DC: Gallaudet University Press, pp. 153-91.

Yoel, Judith. 2009. Canada's Maritime Sign Language. Ph.D. thesis, University of Manitoba, Winnipeg, MB, Canada.

Zeshan, Ulrike, and Connie de Vos. 2012. Sign Languages in Village Communities: Anthropological and Linguistic Insights. Berlin: De Gruyter.

Zeshan, Ulrike, and Hasan Dikyuva. 2013. Documentation of endangered sign languages: The case of Mardin Sign Language. In Keeping Languages Alive: Documentation, Pedagogy and Revitalization. Edited by Mari Jones and Sarah Ogilvie. Cambridge: Cambridge University Press, pp. 29-41. [CrossRef] 